\title{
Color and psychological functioning: a review of theoretical and empirical work
}

\author{
Andrew J. Elliot* \\ Department of Clinical and Social Sciences in Psychology, University of Rochester, Rochester, NY, USA
}

In the past decade there has been increased interest in research on color and psychological functioning. Important advances have been made in theoretical work and empirical work, but there are also important weaknesses in both areas that must be addressed for the literature to continue to develop apace. In this article, I provide brief theoretical and empirical reviews of research in this area, in each instance beginning with a historical background and recent advancements, and proceeding to an evaluation focused on weaknesses that provide guidelines for future research. I conclude by reiterating that the literature on color and psychological functioning is at a nascent stage of development, and by recommending patience and prudence regarding conclusions

OPEN ACCESS

Edited by:

Gregory R. Maio,

Cardiff University, UK

Reviewed by:

Netta Weinstein,

University of Essex, UK

lan Stephen,

Macquarie University, Australia

*Correspondence:

Andrew J. Elliot,

Department of Clinical and Social Sciences in Psychology, University of

Rochester, Intercampus Drive, Rochester, NY 14627, USA

andye@psych.rochester.edu

Specialty section:

This article was submitted to

Personality and Social Psychology, a section of the journal Frontiers in

Psychology

Received: 25 November 2014 Accepted: 16 March 2015

Published: 02 April 2015

Citation:

Elliot AJ (2015) Color and psychological functioning: a review of theoretical and empirical work.

Front. Psychol. 6:368. doi: 10.3389/fpsyg.2015.00368 about theory, findings, and real-world application.

Keywords: color, psychological functioning, hue, lightness, chroma

The past decade has seen enhanced interest in research in the area of color and psychological functioning. Progress has been made on both theoretical and empirical fronts, but there are also weaknesses on both of these fronts that must be attended to for this research area to continue to make progress. In the following, I briefly review both advances and weaknesses in the literature on color and psychological functioning.

\section{Theoretical Work}

\section{Background and Recent Developments}

Color has fascinated scholars for millennia (Sloane, 1991; Gage, 1993). Theorizing on color and psychological functioning has been present since Goethe (1810) penned his Theory of Colors, in which he linked color categories (e.g., the "plus" colors of yellow, red-yellow, yellow-red) to emotional responding (e.g., warmth, excitement). Goldstein (1942) expanded on Goethe's intuitions, positing that certain colors (e.g., red, yellow) produce systematic physiological reactions manifest in emotional experience (e.g., negative arousal), cognitive orientation (e.g., outward focus), and overt action (e.g., forceful behavior). Subsequent theorizing derived from Goldstein's ideas has focused on wavelength, positing that longer wavelength colors feel arousing or warm, whereas shorter wavelength colors feel relaxing or cool (Nakashian, 1964; Crowley, 1993). Other conceptual statements about color and psychological functioning have focused on general associations that people have to colors and their corresponding influence on downstream affect, cognition, and behavior (e.g., black is associated with aggression and elicits aggressive behavior; Frank and Gilovich, 1988; Soldat et al., 1997). Finally, much writing on color and psychological functioning has been completely atheoretical, focused exclusively on finding answers to applied questions (e.g., "What wall color 
facilitates worker alertness and productivity?"). The aforementioned theories and conceptual statements continue to motivate research on color and psychological functioning. However, several other promising theoretical frameworks have also emerged in the past decade, and I review these frameworks in the following.

Hill and Barton (2005) noted that in many non-human animals, including primate species, dominance in aggressive encounters (i.e., superior physical condition) is signaled by the bright red of oxygenated blood visible on highly vascularized bare skin. Artificial red (e.g., on leg bands) has likewise been shown to signal dominance in non-human animals, mimicking the natural physiological process (Cuthill et al., 1997). In humans in aggressive encounters, a testosterone surge produces visible reddening on the face and fear leads to pallor (Drummond and Quay, 2001; Levenson, 2003). Hill and Barton (2005) posited that the parallel between humans and non-humans present at the physiological level may extend to artificial stimuli, such that wearing red in sport contests may convey dominance and lead to a competitive advantage.

Other theorists have also utilized a comparative approach in positing links between skin coloration and the evaluation of conspecifics. Changizi et al. (2006) and Changizi (2009) contend that trichromatic vision evolved to enable primates, including humans, to detect subtle changes in blood flow beneath the skin that carry important information about the emotional state of the conspecific. Increased red can convey anger, embarrassment, or sexual arousal, whereas increased bluish or greenish tint can convey illness or poor physiological condition. Thus, visual sensitivity to these color modulations facilitates various forms of social interaction. In similar fashion, Stephen et al. (2009) and Stephen and McKeegan (2010) propose that perceivers use information about skin coloration (perhaps particularly from the face, Tan and Stephen, 2012) to make inferences about the attractiveness, health, and dominance of conspecifics. Redness (from blood oxygenization) and yellowness (from carotenoids) are both seen as facilitating positive judgments. Fink et al. (2006) and Fink and Matts (2007) posit that the homogeneity of skin coloration is an important factor in evaluating the age, attractiveness, and health of faces.

Elliot and Maier (2012) have proposed color-in-context theory, which draws on social learning, as well as biology. Some responses to color stimuli are presumed to be solely due to the repeated pairing of color and particular concepts, messages, and experiences. Others, however, are presumed to represent a biologically engrained predisposition that is reinforced and shaped by social learning. Through this social learning, color associations can be extended beyond natural bodily processes (e.g., blood flow modulations) to objects in close proximity to the body (e.g., clothes, accessories). Thus, for example, red may not only increase attractiveness evaluations when viewed on the face, but also when viewed on a shirt or dress. As implied by the name of the theory, the physical and psychological context in which color is perceived is thought to influence its meaning and, accordingly, responses to it. Thus, blue on a ribbon is positive (indicating first place), but blue on a piece of meat is negative (indicating rotten), and a red shirt may enhance the attractiveness of a potential mate (red $=$ sex/romance), but not of a person evaluating one's competence (red = failure/danger).

Meier and Robinson (2005) and Meier (in press) have posited a conceptual metaphor theory of color. From this perspective, people talk and think about abstract concepts in concrete terms grounded in perceptual experience (i.e., they use metaphors) to help them understand and navigate their social world (Lakoff and Johnson, 1999). Thus, anger entails reddening of the face, so anger is metaphorically described as "seeing red," and positive emotions and experiences are often depicted in terms of lightness (rather than darkness), so lightness is metaphorically linked to good ("seeing the light") rather than bad ("in the dark"). These metaphoric associations are presumed to have implications for important outcomes such as morality judgments (e.g., white things are viewed as pure) and stereotyping (e.g., dark faces are viewed more negatively).

For many years it has been known that light directly influences physiology and increases arousal (see Cajochen, 2007, for a review), but recently theorists have posited that such effects are wavelength dependent. Blue light, in particular, is posited to activate the melanopsin photoreceptor system which, in turn, activates the brain structures involved in sub-cortical arousal and higher-order attentional processing (Cajochen et al., 2005; Lockley et al., 2006). As such, exposure to blue light is expected to facilitate alertness and enhance performance on tasks requiring sustained attention.

\section{Evaluation and Recommendations}

Drawing on recent theorizing in evolutionary psychology, emotion science, retinal physiology, person perception, and social cognition, the aforementioned conceptualizations represent important advances to the literature on color and psychological functioning. Nevertheless, theory in this area remains at a nascent level of development, and the following weaknesses may be identified.

First, the focus of theoretical work in this area is either extremely specific or extremely general. A precise conceptual proposition such as red signals dominance and leads to competitive advantage in sports (Hill and Barton, 2005) is valuable in that it can be directly translated into a clear, testable hypothesis; however, it is not clear how this specific hypothesis connects to a broader understanding of color-performance relations in achievement settings more generally. On the other end of the spectrum, a general conceptualization such as color-in-context theory (Elliot and Maier, 2012) is valuable in that it offers several widely applicable premises; however, these premises are only vaguely suggestive of precise hypotheses in specific contexts. What is needed are mid-level theoretical frameworks that comprehensively, yet precisely explain and predict links between color and psychological functioning in specific contexts (for emerging developments, see Pazda and Greitemeyer, in press; Spence, in press; Stephen and Perrett, in press).

Second, the extant theoretical work is limited in scope in terms of range of hues, range of color properties, and direction of influence. Most theorizing has focused on one hue, red, which is understandable given its prominence in nature, on the body, and in society (Changizi, 2009; Elliot and Maier, 2014); however, 
other hues also carry important associations that undoubtedly have downstream effects (e.g., blue: Labrecque and Milne, 2012; green: Akers et al., 2012). Color has three basic properties: hue, lightness, and chroma (Fairchild, 2013). Variation in any or all of these properties could influence downstream affect, cognition, or behavior, yet only hue is considered in most theorizing (most likely because experientially, it is the most salient color property). Lightness and chroma also undoubtedly have implications for psychological functioning (e.g., lightness: Kareklas et al., 2014; chroma: Lee et al., 2013); lightness has received some attention within conceptual metaphor theory (Meier, in press; see also Prado-León and Rosales-Cinco, 2011), but chroma has been almost entirely overlooked, as has the issue of combinations of hue, lightness, and chroma. Finally, most theorizing has focused on color as an independent variable rather than a dependent variable; however, it is also likely that many situational and intrapersonal factors influence color perception (e.g., situational: Bubl et al., 2009; intrapersonal: Fetterman et al., 2015).

Third, theorizing to date has focused primarily on main effects, with only a modicum of attention allocated to the important issue of moderation. As research literatures develop and mature, they progress from a sole focus on "is" questions ("Does $\mathrm{X}$ influence Y?") to additionally considering "when" questions ("Under what conditions does $\mathrm{X}$ influence $\mathrm{Y}$ and under what conditions does X not influence Y?"). These "second generation" questions (Zanna and Fazio, 1982, p. 283) can seem less exciting and even deflating in that they posit boundary conditions that constrain the generalizability of an effect. Nevertheless, this step is invaluable in that it adds conceptual precision and clarity, and begins to address the issue of real-world applicability. All color effects undoubtedly depend on certain conditions - culture, gender, age, type of task, variant of color, etc. - and acquiring an understanding of these conditions will represent an important marker of maturity for this literature (for movement in this direction, see Schwarz and Singer, 2013; Tracy and Beall, 2014; Bertrams et al., 2015; Buechner et al., in press; Young, in press). Another, more succinct, way to state this third weakness is that theorizing in this area needs to take context, in all its forms, more seriously.

\section{Empirical Work}

\section{Background and Recent Developments}

Empirical work on color and psychological functioning dates back to the late 19th century (Féré, 1887; see Pressey, 1921, for a review). A consistent feature of this work, from its inception to the past decade, is that it has been fraught with major methodological problems that have precluded rigorous testing and clear interpretation (O'Connor, 2011). One problem has been a failure to attend to rudimentary scientific procedures such as experimenter blindness to condition, identifying, and excluding color deficient participants, and standardizing the duration of color presentation or exposure. Another problem has been a failure to specify and control for color at the spectral level in manipulations. Without such specification, it is impossible to know what precise combination of color properties was investigated, and without such control, the confounding of focal and non-focal color properties is inevitable (Whitfield and Wiltshire, 1990; Valdez and Mehrabian, 1994). Yet another problem has been the use of underpowered samples. This problem, shared across scientific disciplines (Maxwell, 2004), can lead to Type I errors, Type II errors, and inflated effect sizes (Fraley and Vazire, 2014; Murayama et al., 2014). Together, these methodological problems have greatly hampered progress in this area.

Although some of the aforementioned problems remain (see "Evaluation and Recommendations" below), others have been rectified in recent work. This, coupled with advances in theory development, has led to a surge in empirical activity. In the following, I review the diverse areas in which color work has been conducted in the past decade, and the findings that have emerged. Space considerations require me to constrain this review to a brief mention of central findings within each area. I focus on findings with humans (for reviews of research with non-human animals, see Higham and Winters, in press; Setchell, in press) that have been obtained in multiple (at least five) independent labs. Table 1 provides a summary, as well as representative examples and specific references.

In research on color and selective attention, red stimuli have been shown to receive an attentional advantage (see Folk, in press, for a review). Research on color and alertness has shown that blue light increases subjective alertness and performance on attention-based tasks (see Chellappa et al., 2011, for a review). Studies on color and athletic performance have linked wearing red to better performance and perceived performance in sport competitions and tasks (see Maier et al., in press, for a review). In research on color and intellectual performance, viewing red prior to a challenging cognitive task has been shown to undermine performance (see Shi et al., 2015, for a review). Research focused on color and aggressiveness/dominance evaluation has shown that viewing red on self or other increases appraisals of aggressiveness and dominance (see Krenn, 2014, for a review). Empirical work on color and avoidance motivation has linked viewing red in achievement contexts to increased caution and avoidance (see Elliot and Maier, 2014, for a review). In research on color and attraction, viewing red on or near a female has been shown to enhance attraction in heterosexual males (see Pazda and Greitemeyer, in press, for a review). Research on color and store/company evaluation has shown that blue on stores/logos increases quality and trustworthiness appraisals (see Labrecque and Milne, 2012, for a review). Finally, empirical work on color and eating/drinking has shown that red influences food and beverage perception and consumption (see Spence, in press, for a review).

\section{Evaluation and Recommendations}

The aforementioned findings represent important contributions to the literature on color and psychological functioning, and highlight the multidisciplinary nature of research in this area. Nevertheless, much like the extant theoretical work, the extant empirical work remains at a nascent level of development, due, in part, to the following weaknesses. 


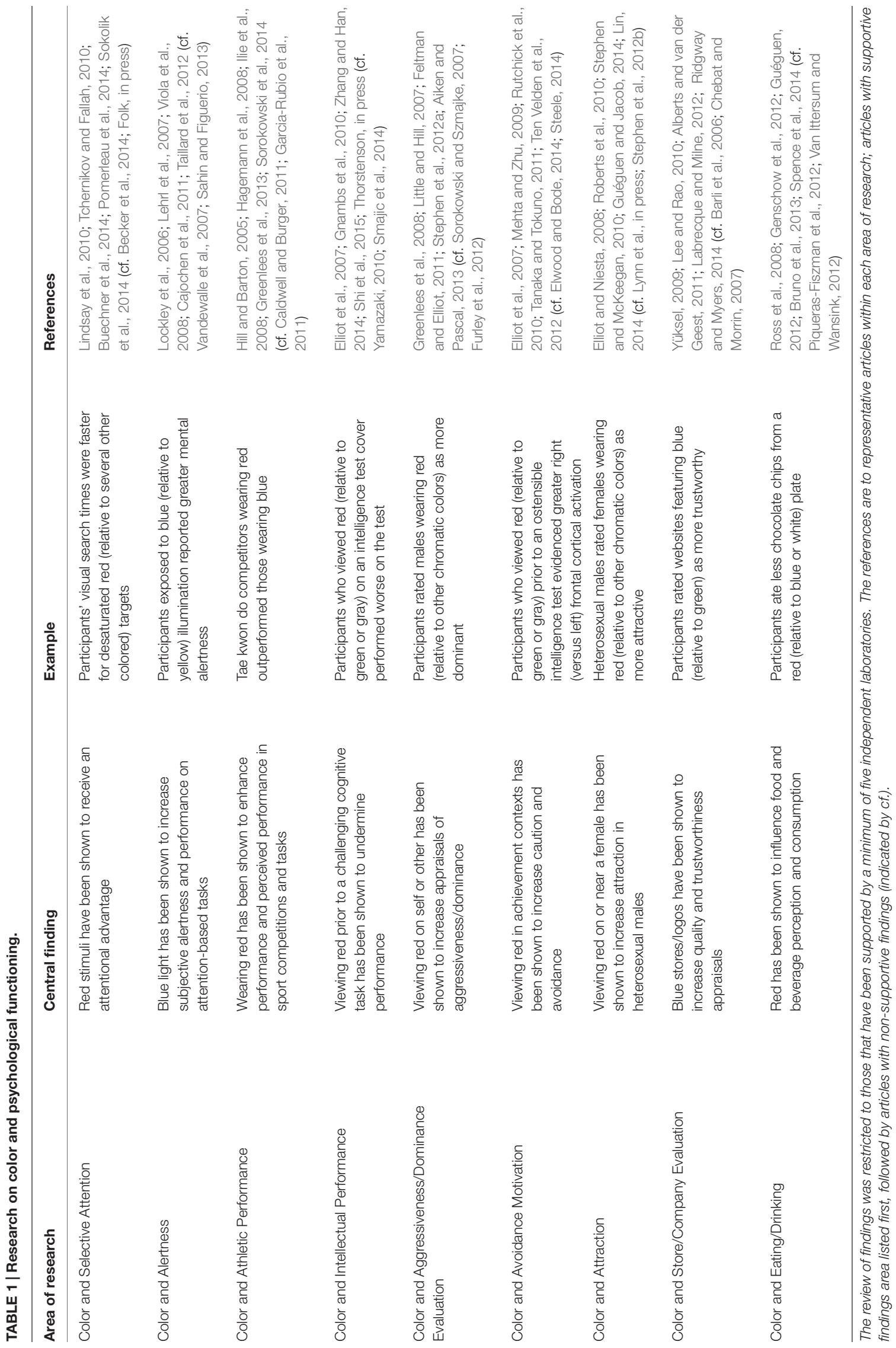


First, although in some research in this area color properties are controlled for at the spectral level, in most research it (still) is not. Color control is typically done improperly at the device (rather than the spectral) level, is impossible to implement (e.g., in web-based platform studies), or is ignored altogether. Color control is admittedly difficult, as it requires technical equipment for color assessment and presentation, as well as the expertise to use it. Nevertheless, careful color control is essential if systematic scientific work is to be conducted in this area. Findings from uncontrolled research can be informative in initial explorations of color hypotheses, but such work is inherently fraught with interpretational ambiguity (Whitfield and Wiltshire, 1990; Elliot and Maier, 2014) that must be subsequently addressed.

Second, color perception is not only a function of lightness, chroma, and hue, but also of factors such as viewing distance and angle, amount and type of ambient light, and presence of other colors in the immediate background and general environmental surround (Hunt and Pointer, 2011; Brainard and Radonjić, 2014; Fairchild, 2015). In basic color science research (e.g., on color physics, color physiology, color appearance modeling, etcetera; see Gegenfurtner and Ennis, in press; Johnson, in press; Stockman and Brainard, in press), these factors are carefully specified and controlled for in order to establish standardized participant viewing conditions. These factors have been largely ignored and allowed to vary in research on color and psychological functioning, with unknown consequences. An important next step for research in this area is to move to incorporate these more rigorous standardization procedures widely utilized by basic color scientists. With regard to both this and the aforementioned weakness, it should be acknowledged that exact and complete control is not actually possible in color research, given the multitude of factors that influence color perception (Committee on Colorimetry of the Optical Society of America, 1953) and our current level of knowledge about and ability to control them (Fairchild, 2015). As such, the standard that must be embraced and used as a guideline in this work is to control color properties and viewing conditions to the extent possible given current technology, and to keep up with advances in the field that will increasingly afford more precise and efficient color management.

Third, although in some research in this area, large, fully powered samples are used, much of the research remains

\section{References}

Aiken, K. D., and Pascal, V. J. (2013). Seeing red, feeling red: how a change in field color influences perceptions. Int. J. Sport Soc. 3, 107-120.

Akers, A., Barton, J., Cossey, R., Gainsford, P., Griffin, M., and Micklewright, D. (2012). Visual color perception in green exercise: positive effects of mood on perceived exertion. Environ. Sci. Technol. 46, 8661-8666. doi: $10.1021 /$ es301685g

Alberts, W., and van der Geest, T. M. (2011). Color matters: color as trustworthiness cue in websites. Tech. Comm. 58, 149-160.

Barli, Ö., Bilgili, B., and Dane, Ş. (2006). Association of consumers' sex and eyedness and lighting and wall color of a store with price attraction and perceived quality of goods and inside visual appeal. Percept. Motor Skill 103, 447-450. doi: 10.2466/PMS.103.6.447-450 underpowered. This is a problem in general, but it is particularly a problem when the initial demonstration of an effect is underpowered (e.g., Elliot and Niesta, 2008), because initial work is often used as a guide for determining sample size in subsequent work (both heuristically and via power analysis). Underpowered samples commonly produce overestimated effect size estimates (Ioannidis, 2008), and basing subsequent sample sizes on such estimates simply perpetuates the problem. Small sample sizes can also lead researchers to prematurely conclude that a hypothesis is disconfirmed, overlooking a potentially important advance (Murayama et al., 2014). Findings from small sampled studies should be considered preliminary; running large sampled studies with carefully controlled color stimuli is essential if a robust scientific literature is to be developed. Furthermore, as the "evidentiary value movement" (Finkel et al., 2015) makes inroads in the empirical sciences, color scientists would do well to be at the leading edge of implementing such rigorous practices as publically archiving research materials and data, designating exploratory from confirmatory analyses, supplementing or even replacing significant testing with "new statistics" (Cumming, 2014), and even preregistering research protocols and analyses (see Finkel et al., 2015, for an overview).

\section{Conclusion}

In both reviewing advances in and identifying weaknesses of the literature on color and psychological functioning, it is important to bear in mind that the existing theoretical and empirical work is at an early stage of development. It is premature to offer any bold theoretical statements, definitive empirical pronouncements, or impassioned calls for application; rather, it is best to be patient and to humbly acknowledge that color psychology is a uniquely complex area of inquiry (Kuehni, 2012; Fairchild, 2013) that is only beginning to come into its own. Findings from color research can be provocative and media friendly, and the public (and the field as well) can be tempted to reach conclusions before the science is fully in place. There is considerable promise in research on color and psychological functioning, but considerably more theoretical and empirical work needs to be done before the full extent of this promise can be discerned and, hopefully, fulfilled.

Becker, S. I., Valuch, C., and Ansorge, U. (2014). Color priming in pop-out search depends on the relative color of the target. Front. Psychol. 5:289. doi: 10.3389/fpsyg.2014.00289

Bertrams, A., Baumeister, R. F., Englert, C., and Furley, P. (2015). Ego depletion in color priming research: self-control strength moderates the detrimental effect of red on cognitive test performance. Pers. Soc. Psychol. B. 41, 311-322. doi: $10.1177 / 0146167214564968$

Brainard, D. H., and Radonjić, A. (2014). "Color constancy" in The New Visual Neurosciences, eds J. Werner and L. Chalupa (Cambridge, MA; MIT Press), $545-556$.

Bruno, N., Martani, M., Corsini, C., and Oleari, C. (2013). The effect of the color red on consuming food does not depend on achromatic (Michelson) contrast and extends to rubbing cream on the skin. Appetite 71, 307-313. doi: 10.1016/j.appet.2013.08.012 
Bubl, E., Kern, E., Ebert, D., Bach, M., and Tebartz van Elst, L. (2009). Seeing gray when feeling blue? Depression can be measures in the eye of the diseased. Biol. Psychiat. 68, 205-208. doi: 10.1016/j.biopsych.2010. 02.009

Buechner, V. L., Maier, M. A., Lichtenfeld, S., and Elliot, A. J. (in press). Emotion expression and color: their joint influence on perceptions of male attractiveness and social position. Curr. Psychol.

Buechner, V. L., Maier, M. A., Lichtenfeld, S., and Schwarz, S. (2014). Red - take a closer look. PLoS ONE 9:e108111. doi: 10.1371/journal.pone.0108111

Cajochen, C. (2007). Alerting effects of light. Sleep Med. Rev. 11, 453-464. doi: 10.1016/j.smrv.2007.07.009

Cajochen, C., Frey, S., Anders, D., Späti, J., Bues, M., Pross, A., et al. (2011). Evening exposure to a light-emitting diodes (LED)-backlit computer screen affects circadian physiology and cognitive performance. J. Appl. Phsysoil. 110, 1432-1438. doi: 10.1152/japplphysiol.00165.2011

Cajochen, C., Münch, M., Kobialka, S., Kräuchi, K., Steiner, R., Oelhafen, P., et al. (2005). High sensitivity of human melatonin, alertness, thermoregulation, and heart rate to short wavelength light. J. Clin. Endocr. Metab. 90, 1311-1316. doi: 10.1210/jc.2004-0957

Caldwell, D. F., and Burger, J. M. (2011). On thin ice: does uniform color really affect aggression in professional hockey? Soc. Psychol. Pers. Sci. 2, 306-310. doi: $10.1177 / 1948550610389824$

Changizi, M. (2009). The Vision Revolution. Dallas, TX: Benbella.

Changizi, M. A., Zhang, Q., and Shimojo, S. (2006). Bare skin, blood and the evolution of primate colour vision. Biol. Lett. 2, 217-221. doi: 10.1098/rsbl. 2006.0440

Chebat, J. C., and Morrin, M. (2007). Colors and cultures: exploring the effects of mall décor on consumer perceptions. J. Bus. Res. 60, 189-196. doi: 10.1016/j.jbusres.2006.11.003

Chellappa, S. L., Steiner, R., Blattner, P., Oelhafen, P., Götz, T., and Cajochen, C. (2011). Non-visual effects of light on melatonin, alertness, and cognitive performance: can blue-enriched light keep us alert? PLOS ONE 26:e16429. doi: 10.1371/journal.pone.0016429

Committee on Colorimetry of the Optical Society of America. (1953). The Science of Color. Washington, DC: Optical Society of America.

Crowley, A. E. (1993). The two dimensional impact of color on shopping. Market. Lett. 4, 59-69. doi: 10.1007/BF00994188

Cumming, G. (2014). The new statistics: why and how. Psychol. Sci. 25, 7-29. doi: $10.1177 / 0956797613504966$

Cuthill, I. C., Hunt, S., Cleary, C., and Clark, C. (1997). Color bands, dominance, and body mass regulation in male zebra finches (Taeniopygia guttata). Proc. $R$. Soc. Lond. B. Sci. 264, 1093-1099. doi: 10.1098/rspb.1997.0151

Drummond, P. D., and Quay, S. H. (2001). The effect of expressing anger on cardiovascular reactivity and facial blood flow in Chinese and Caucasians. Psychophysiology 38, 190-196. doi: 10.1111/1469-8986.3820190

Elliot, A. J., and Maier, M. A. (2012). Color-in-context theory. Adv. Exp. Soc. Psychol. 45, 61-125. doi: 10.1016/B978-0-12-394286-9. 00002-0

Elliot, A. J., and Maier, M. A. (2014). Color psychology: effects of perceiving color on psychological functioning in humans. Ann. Rev. Psychol. 65, 95-120. doi: 10.1146/annurev-psych-010213-115035

Elliot, A. J., Maier, M. A., Moller, A. C., Friedman, R., and Meinhardt, J. (2007). Color and psychological functioning: the effect of red on performance attainment. J. Exp. Psychol. Gen. 136, 154-168. doi: 10.1037/0096-3445.136. 1.154

Elliot, A. J., and Niesta, D. (2008). Romantic red: red enhances men's attraction to women. J. Personal. Soc. Psychol. 95, 1150-1164. doi: 10.1037/0022 3514.95.5.1150

Elwood, J. A., and Bode, J. (2014). Student preferences vis-à-vis teacher feedback in university EFL writing classes in Japan. System 42, 333-343. doi: 10.1016/j.system.2013.12.023

Fairchild, M. D. (2013). Color Appearance Models, 3rd Edn. New York, NY: Wiley Press. doi: 10.1002/9781118653128

Fairchild, M. D. (2015). Seeing, adapting to, and reproducing the appearance of nature. Appl. Optics 54, B107-B116. doi: 10.1364/AO.54.00B107

Feltman, R., and Elliot, A. J. (2011). The influence of red on perceptions of dominance and threat in a competitive context. J. Sport Exerc. Psychol. 33, 308-314.
Fetterman, A. K., Liu, T., and Robinson, M. D. (2015). Extending color psychology to the personality realm: interpersonal hostility varied by red preferences and perceptual biases. J. Personal. 83, 106-116. doi: 10.1111/jopy.12087

Féré, C. (1887). Note sur les conditions physiologiques des émotions. Revue Phil. 24, 561-581.

Fink, B., Grammer, K., and Matts, P. J. (2006). Visible skin color distribution plays a role in the perception of age, attractiveness, and health in female faces. Evol. Hum. Behav. 27, 433-442. doi: 10.1016/j.evolhumbehav.2006.08.007

Fink, B., and Matts, P. J. (2007). The effects of skin colour distribution and topography cues on the perception of female age and health. J. Eur. Acad. Derm. 22, 493-498. doi: 10.1111/j.1468-3083.2007.02512.x

Finkel, E. J., Eastwick, P. W., and Reis, H. T. (2015). Best research practices in psychology: Illustrating epistemological and pragmatic considerations with the case of relationship science. J. Pers. Soc. Psychol. 108, 275-297. doi: 10.1037/pspi0000007

Folk, C. L. (in press). "The role of color in the voluntary and involuntary guidance of selective attention," in Handbook of Color Psychology, eds A. Elliot, M. Fairchild, and A. Franklin (Cambridge: Cambridge University Press).

Fraley, R. C., and Vazire, S. (2014). The N-pact factor: evaluating the quality of empirical journals with respect to sample size and statistical power. PLoS ONE 9:e109019. doi: 10.1371/journal.pone.0109019

Frank, M. G., and Gilovich, T. (1988). The dark side of self and social perception: black uniforms and aggression in professional sports. J. Pers. Soc. Psychol. 54, 74-85. doi: 10.1037/0022-3514.54.1.74

Furley, P., Dicks, M., and Memmert, D. (2012). Nonverbal behavior in soccer: the influence of dominant and submissive body language on the impression formation and expectancy of success of soccer players. J. Sport Exerc. Psychol. 34, 61-82.

Gage, J. (1993). Color and Culture: Practice and Meaning from Antiquity to Abstraction. Berkeley, CA: University of California Press.

Garcia-Rubio, M. A., Picazo-Tadeo, A. J., and González-Gómez, F. (2011). Does a red shirt improve sporting performance? Evidence from Spanish football. Appl. Econ. Lett. 18, 1001-1004. doi: 10.1080/13504851.2010.520666

Gegenfurtner, K. R., and Ennis, R. (in press). "Fundamentals of color vision II: higher order color processing," in Handbook of Color Psychology, eds A. Elliot, M. Fairchild, and A. Franklin (Cambridge: Cambridge University Press).

Genschow, O., Reutner, L., and Wänke, M. (2012). The color red reduces snack food and soft Drink intake. Appetite 58, 699-702. doi: 10.1016/j.appet.2011.12.023

Gnambs, T., Appel, M., and Batinic, B. (2010). Color red in web-based knowledge testing. Comput. Hum. Behav. 26, 1625-1631. doi: 10.1016/j.chb.2010.06.010

Goethe, W. (1810). Theory of Colors. London: Frank Cass.

Goldstein, K. (1942). Some experimental observations concerning the influence of colors on the function of the organism. Occup. Ther. Rehab. 21, 147-151. doi: 10.1097/00002060-194206000-00002

Greenlees, I. A., Eynon, M., and Thelwell, R. C. (2013). Color of soccer goalkeepers' uniforms influences the outcomed of penalty kicks. Percept. Mot. Skill. 116, 1-10. doi: 10.2466/30.24.PMS.117x14z6

Greenlees, I., Leyland, A., Thelwell, R., and Filby, W. (2008). Soccer penalty takers' uniform color and pre-penalty kick gaze affect the impressions formed of them by opposing goalkeepers. J. Sport Sci. 26, 569-576. doi: $10.1080 / 02640410701744446$

Guéguen, N. (2012). Color and women attractiveness: when red clothed women are perceived to have more intense sexual intent. J. Soc. Psychol. 152, 261-265. doi: $10.1080 / 00224545.2011 .605398$

Guéguen, N., and Jacob, C. (2014). Coffee cup color and evaluation of a beverage's "warmth quality." Color Res. Appl. 39, 79-81. doi: 10.1002/col.21757

Hagemann, N., Strauss, B., and Leißing, J. (2008). When the referee sees red. Psychol. Sci. 19, 769-771. doi: 10.1111/j.1467-9280.2008.02155.x

Higham, J. P., and Winters, S. (in press). "Color and mate choice in non-human animals," in Handbook of Color Psychology, eds A. Elliot, M. Fairchild, and A. Franklin (Cambridge: Cambridge University Press).

Hill, R. A., and Barton, R. A. (2005). Red enhances human performance in contests. Nature 435, 293. doi: 10.1038/435293a

Hunt, R. W. G., and Pointer, M. R. (2011). Measuring Colour, 4th Edn. New York, NY: Wiley Press. doi: 10.1002/9781119975595

Ilie, A., Ioan, S., Zagrean, L., and Moldovan, M. (2008). Better to be red than blue in virtual competition. Cyberpsychol. Behav. 11, 375-377. doi: 10.1089/cpb.2007.0122 
Ioannidis, J. P. A. (2008). Why most discovered true associations are inflated. Epidemiology 19, 640-648. doi: 10.1097/EDE.0b013e31818131e7

Johnson, G. M. (in press). "Color appearance phenomena and visual illusions," in Handbook of Color Psychology, eds A. Elliot, M. Fairchild, and A. Franklin (Cambridge: Cambridge University Press).

Kareklas, I., Brunel, F. F., and Coulter, R. A. (2014). Judgment is not color blind: the impact of automatic color preference on product advertising preferences. J. Consum. Psychol. 24, 87-95. doi: 10.1016/j.jcps.2013.09.005

Krenn, B. (2014). The impact of uniform color on judging tackles in association football. Psychol. Sport Exerc. 15, 222-225. doi: 10.1016/j.psychsport.2013.11.007

Kuehni, R. (2012). Color: An Introduction to Practice and Principles, 3rd Edn. New York, NY: Wiley. doi: 10.1002/9781118533567

Labrecque, L. L., and Milne, G. R. (2012). Exciting red and competent blue: the importance of color in marketing. J. Acad. Mark. Sci. 40, 711-727. doi: 10.1007/s11747-010-0245-y

Lakoff, G., and Johnson, M. (1999). Philosophy in the Flesh: The Embodied Mind and its Challenges to Western Thought. New York, NY: Basic Books.

Lee, S., Lee, K., Lee, S., and Song, J. (2013). Origins of human color preference for food. J. Food Eng. 119, 508-515. doi: 10.1016/j.jfoodeng.2013.06.021

Lee, S., and Rao, V. S. (2010). Color and store choice in electronic commerce: the explanatory role of trust. J. Electr. Commer. Res. 11, 110-126.

Lehrl, S., Gerstmeyer, K., Jacob, J. H., Frieling, H., Henkel, A. W., Meyrer, R., et al. (2007). Blue light improves cognitive performance. J. Neural Trans. 114, 457-460. doi: 10.1007/s00702-006-0621-4

Levenson, R. W. (2003). Blood, sweat, and fears: the automatic architecture of emotion. Ann. N. Y. Acad Sci. 1000, 348-366. doi: 10.1196/annals.1280.016

Lin, H. (2014). Red-colored products enhance the attractiveness of women. Displays 35, 202-205. doi: 10.1016/j.displa.2014.05.009

Lindsay, D. T., Brown, A. M., Reijnen, E., Rich, A. N., Kuzmova, Y. I., and Wolfe, J. M. (2010). Color channels, not color appearance of color categories, guide visual search for desaturated color targets. Psychol. Sci. 21, 1208-1214. doi: $10.1177 / 0956797610379861$

Little, A. C., and Hill, R. A. (2007). Attribution to red suggests special role in dominance signaling. J. Evol. Psychol. 5, 161-168. doi: 10.1556/JEP.2007.1008

Lockley, S. W., Evans, E. E., Scheer, F. A., Brainard, G. C., Czeisler, C. A., and Aeschbach, D. (2006). Short-wavelength sensitivity for the direct effects of light on alertness, vigilance, and the waking electroencephalogram in humans. Sleep $29,161-168$.

Lynn, M., Giebelhausen, M., Garcia, S., Li, Y., and Patumanon, I. (in press). Clothing color and tipping: an attempted replication and extension. J. Hosp. Tourism Res. doi: 10.1177/1096348013504001

Maier, M. A., Hill, R., Elliot, A. J., and Barton, R. A. (in press). "Color in achievement contexts in humans," in Handbook of Color Psychology, eds A. Elliot, M. Fairchild, and A. Franklin (Cambridge: Cambridge University Press).

Maxwell, S. (2004). The persistence of underpowered studies in psychological research: causes and consequences. Psychol. Methods 9, 147-163. doi: 10.1037/1082-989X.9.2.147

Mehta, R., and Zhu, R. (2009). Blue or red? Exploring the effect of color on cognitive task performances. Science 323, 1226-1229. doi: 10.1126/science. 1169144

Meier, B. P. (in press). "Do metaphors color our perception of social life?" in Handbook of Color sychology, eds A. Elliot, M. Fairchild, and A. Franklin (Cambridge: Cambridge University Press).

Meier, B. P., and Robinson, M. D. (2005). The metaphorical representation of affect. Metaphor Symbol. 20, 239-257. doi: 10.1207/s15327868ms2004_1

Murayama, K., Pekrun, R., and Fiedler, K. (2014). Research practices that can prevent an inflation of false-positive rates. Personal. Soc. Psychol. Rev. 18, 107-118. doi: $10.1177 / 1088868313496330$

Nakashian, J. S. (1964). The effects of red and green surroundings on behavior. J. Gen. Psychol. 70, 143-162. doi: 10.1080/00221309.1964.9920584

O'Connor, Z. (2011). Colour psychology and colour therapy: caveat emptor. Color Res. Appl. 36, 229-334. doi: 10.1002/col.20597

Pazda, A. D., and Greitemeyer, T. (in press). "Color in romantic contexts in humans," in Handbook of Color Psychology, eds A. Elliot, M. Fairchild, and A. Franklin (Cambridge: Cambridge University Press).

Piqueras-Fiszman, B., Alcaide, J., Roura, E., and Spence, C. (2012). Is it the plate or is it the food? Assessing the influence of the color (black or white) and shape of the plate on the perception of food placed on it. Food Qual. Prefer. 24, 205-208. doi: 10.1016/j.foodqual.2011.08.011

Pomerleau, V. J., Fortier-Gauthier, U., Corriveau, I., Dell'Acqua, R., and Jolicœur, P. (2014). Colour-specific differences in attentional deployment for equiluminant pop-out colours: evidence from lateralized potentials. Int. J. Psychophysiol. 91, 194-205. doi: 10.1016/j.jpsycho.2013.10.016

Prado-León, L. R., and Rosales-Cinco, R. A. (2011). "Effects of lightness and saturation on color associations in the Mexican population," in New Directions in Colour Studies, eds C. Biggam, C. Hough, C. Kay, and D. Simmons (Amsterdam, NL: John Benjamins Publishing Company), 389-394.

Pressey, S. L. (1921). The influence of color upon mental and motor efficiency. Am. J. Psychol. 32, 327-356. doi: 10.2307/1413999

Ridgway, J., and Myers, B. (2014). A study on brand personality: consumers' perceptions of colours used in fashion brand logos. Int. J. Fash. Des. Tech. Educ. 7, 50-57. doi: 10.1080/17543266.2013.877987

Roberts, S. C., Owen, R. C., and Havlicek, J. (2010). Distinguishing between perceiver and wearer effects in clothing color-associated attributions. Evol. Psychol. $8,350-364$.

Ross, C. F., Bohlscheid, J., and Weller, K. (2008). Influence of visual masking technique on the assessment of 2 red wines by trained consumer assessors. J. Food Sci. 73, S279-S285. doi: 10.1111/j.1750-3841.2008. 00824.x

Rutchick, A. M., Slepian, M. L., and Ferris, B. D. (2010). The pen is mightier than the word: object priming of evaluative standards. Eur. J. Soc. Psychol. 40, 704-708. doi: 10.1002/ejsp.753

Sahin, L., and Figuerio, M. G. (2013). Alerting effects of short-wavelength (blue) and long-wavelength (red) lights in the afternoon. Physiol. Behav. 116, 1-7. doi: 10.1016/j.physbeh.2013.03.014

Schwarz, S., and Singer, M. (2013). Romantic red revisited: red enhances men's attraction to young, but not menopausal women. J. Exp. Soc. Psychol. 49, 161-164. doi: 10.1016/j.jesp.2012.08.004

Setchell, J. (in press). "Color in competition contexts in non-human animals," in Handbook of Color Psychology, eds A. Elliot, M. Fairchild, and A. Franklin (Cambridge: Cambridge University Press).

Shi, J., Zhang, C., and Jiang, f. (2015). Does red undermine individuals' intellectual performance? A test in China. Int. J. Psychol. 50, 81-84. doi: 10.1002/ijop. 12076

Sloane, P. (1991). Primary Sources, Selected Writings on Color from Aristotle to Albers. New York, NY: Design Press.

Smajic, A., Merritt, S., Banister, C., and Blinebry, A. (2014). The red effect, anxiety, and exam performance: a multistudy examination. Teach. Psychol. 41, 37-43. doi: $10.1177 / 0098628313514176$

Sokolik, K., Magee, R. G., and Ivory, J. D. (2014). Red-hot and ice-cold ads: the influence of web ads' warm and cool colors on click-through ways. J. Interact. Advert. 14, 31-37. doi: 10.1080/15252019.2014.907757

Soldat, A. S., Sinclair, R. C., and Mark, M. M. (1997). Color as an environmental processing cue: external affective cues can directly affect processing strategy without affecting mood. Soc. Cogn. 15, 55-71. doi: 10.1521/soco.1997.15.1.55

Sorokowski, P., and Szmajke, A. (2007). How does the "red wins: effect work? The role of sportswear colour during sport competitions. Pol. J. Appl. Psychol. 5, 71-79.

Sorokowski, P., Szmajke, A., Hamamura, T., Jiang, F., and Sorakowska, A. (2014). "Red wins," "black wins," "blue loses" effects are in the eye of the beholder, but they are culturally niversal: a cross-cultural analysis of the influence of outfit colours on sports performance. Pol. Psychol. Bull. 45, 318-325. doi: 10.2478/ppb-2014-0039

Spence, C. (in press). "Eating with our eyes," in Handbook of Color Psychology, eds A. Elliot, M. Fairchild, and A. Franklin (Cambridge: Cambridge University Press).

Spence, C., Velasco, C., and Knoeferle, K. (2014). A large sampled study on the influence of the multisensory environment on the wine drinking experience. Flavour 3, 8. doi: 10.1186/2044-7248-3-8

Steele, K. M. (2014). Failure to replicate the Mehta and Zhu (2009) colorpriming effect on anagram solution times. Psychon. B. Rev. 21, 771-776. doi: 10.3758/s13423-013-0548-3

Stephen, I. D., Law Smith, M. J., Stirrat, M. R., and Perrett, D. I. (2009). Facial skin coloration affects perceived health of human faces. Int. J. Primatol. 30, 845-857. doi: $10.1007 /$ s10764-009-9380-z 
Stephen, I. D., and McKeegan, A. M. (2010). Lip colour affects perceived sex typicality and attractiveness of human faces. Perception 39, 1104-1110. doi: $10.1068 / \mathrm{p} 6730$

Stephen, I. D., Oldham, F. H., Perrett, D. I., and Barton, R. A. (2012a). Redness enhances perceived aggression, dominance and attractiveness in men's faces. Evol. Psychol. 10, 562-572.

Stephen, I. D., Scott, I. M. L., Coetzee, V., Pound, N., Perrett, D. I., and PentonVoak, I. S. (2012b). Cross-cultural effects of color, but not morphological masculinity, on perceived attractiveness of men's faces. Evol. Hum. Behav. 33, 260-267. doi: 10.1016/j.evolhumbehav.2011.10.003

Stephen, I. D., and Perrett, D. I. (in press). "Color and face perception," in Handbook of Color Psychology, eds A. Elliot, M. Fairchild, and A. Franklin (Cambridge: Cambridge University Press).

Stockman, A., and Brainard, D. H. (in press). "Fundamentals of color vision I: processing in the eye," in Handbook of Color Psychology, eds A. Elliot, M. Fairchild, and A. Franklin (Cambridge: Cambridge University Press).

Taillard, J., Capelli, A., Sagaspe, P., Anund, A., and Akerstadt, T. (2012). In-car nocturnal blue light exposure improves motorway driving: a randomized controlled trial. PLOS ONE 7:e46750. doi: 10.1371/journal.pone. 0046750

Tan, K. W., and Stephen, I. D. (2012). Colour detection thresholds in faces and colour patches. Perception 42, 733-741. doi: 10.1068/p7499

Tanaka, A., and Tokuno, Y. (2011). The effect of the color red on avoidance motivation. Soc. Behav. Pers. 39, 287-288. doi: 10.2224/sbp.2011.39.2.287

Tchernikov, I., and Fallah, M. (2010). A color hierarchy for automatic target selection. PLOS ONE 5:e9338. doi: 10.1371/journal.pone. 0009338

Thorstenson, C. A. (in press). Functional equivalence of the color red and enacted avoidance behavior? Replication and empirical integration. Soc. Psychol.

Tracy, J. L., and Beall, A. T. (2014). The impact of weather on women's tendency to wear red pink when at high risk for conception. PLOS ONE 9:e88852. doi: 10.1371/journal.pone.0088852

Ten Velden, F. S., Baas, M., Shalvi, S., Preenen, P. T. Y., and De Dreu, C. K. W. (2012). In competitive interaction displays of red increase actors' competitive approach and perceivers' withdrawal. J. Exp. Soc. Psychol. 48, 1205-1208. doi: 10.1016/j.jesp.2012.04.004

Valdez, P., and Mehrabian, A. (1994). Effects of color on emotions. J. Exp. Psychol. Gen. 123, 394-409. doi: 10.1037/0096-3445.123.4.394
Van Ittersum, K., and Wansink, B. (2012). Plate size and color suggestability, The Deboeuf Illusion's bias on serving and eating behavior. J. Consum. Res. 39, 215-228. doi: 10.1086/662615

Vandewalle, G., Schmidt, C., Albouy, G., Sterpenich, V., Darsaud, A., Rauchs, G., et al. (2007). Brain responses to violet, blue, and green monochromatic light exposures in humans: prominent role of blue light and the brainstem. PLoS ONE 11:e1247. doi: 10.1371/journal.pone.0001247

Viola, A. U., James, L. M., Schlangen, L. J. M., and Dijk, D. J. (2008). Blueenriched white lightin the workplace improves self-reported alertness, performance and sleep quality. Scan. J. Work Environ. Health 34, 297-306. doi: $10.5271 /$ sjweh. 1268

Whitfield, T. W., and Wiltshire, T. J. (1990). Color psychology: a critical review. Gen. Soc. Gen. Psychol. 116, 385-411.

Yamazaki, A. K. (2010). An analysis of background-color effects on the scores of a computer-based English test. KES Part II LNI. 6277, 630-636. doi: 10.1007/9783-642-15390-7_65

Young, S. (in press). The effect of red on male perceptions of female attractiveness: moderationby baseline attractiveness of female faces. Eur. J. Soc. Psychol.

Yüksel, A. (2009). Exterior color and perceived retail crowding: effects on tourists' shoppingquality inferences and approach behaviors. J. Qual. Assur. Hosp. Tourism 10, 233-254. doi: 10.1080/15280080903183383

Zanna, M. P., and Fazio, R. H. (1982). "The attitude behavior relation: Moving toward a third generation of research," in The Ontario Symposium, Vol. 2, eds M. Zanna, E. T. Higgins, and C. Herman (Hillsdale, NJ: Lawrence Erlbaum Associates, Inc.), 283-301.

Zhang, T., and Han, B. (2014). Experience reverses the red effect among Chinese stockbrokers. PLoS ONE 9:e89193. doi: 10.1371/journal.pone.0089193

Conflict of Interest Statement: The author declares that the research was conducted in the absence of any commercial or financial relationships that could be construed as a potential conflict of interest.

Copyright $\odot 2015$ Elliot. This is an open-access article distributed under the terms of the Creative Commons Attribution License (CC BY). The use, distribution or reproduction in other forums is permitted, provided the original author(s) or licensor are credited and that the original publication in this journal is cited, in accordance with accepted academic practice. No use, distribution or reproduction is permitted which does not comply with these terms. 